\title{
Health systems and gender in post-conflict contexts: building back better?
}

Valerie Percival ${ }^{1 *}$, Esther Richards², Tammy MacLean ${ }^{3}$ and Sally Theobald ${ }^{2}$

\begin{abstract}
The post-conflict or post-crisis period provides the opportunity for wide-ranging public sector reforms: donors fund rebuilding and reform efforts, social norms are in a state of flux, and the political climate may be conducive to change. This reform period presents favourable circumstances for the promotion of gender equity in multiple social arenas, including the health system. As part of a larger research project that explores whether and how gender equity considerations are taken into account in the reconstruction and reform of health systems in conflict-affected and post conflict countries, we undertook a narrative literature review based on the questions "How gender sensitive is the reconstruction and reform of health systems in post conflict countries, and what factors need to be taken into consideration to build a gender equitable health system?" We used the World Health Organisation's (WHO) six building blocks as a framework for our analysis; these six building blocks are: 1) health service delivery/provision, 2) human resources, 3) health information systems, 4) health system financing, 5) medical products and technologies, and 6) leadership and governance.

The limited literature on gender equity in health system reform in post conflict settings demonstrates that despite being an important political and social objective of the international community's engagement in conflict-affected states, gender equity has not been fully integrated into post-conflict health system reform. Our review was therefore iterative in nature: To establish what factors need to be taken into consideration to build gender equitable health systems, we reviewed health system reforms in low and middle-income settings. We found that health systems literature does not sufficiently address the issue of gender equity. With this finding, we reflected on the key components of a gender-equitable health system that should be considered as part of health system reform in conflict-affected and post-conflict states. Given the benefits of gender equity for broader social and economic well-being, it is clearly in the interests of donors and policy makers to address this oversight in future health reform efforts.
\end{abstract}

Keywords: Health system reform, Post-conflict, Gender equity and health

\section{Background}

For the vast majority of the world's population, social and cultural perceptions regarding gender norms and roles devalue and denigrate women and girls, and undermine and restrict their social status, livelihood opportunities, behaviours and freedoms. These same norms encourage excessive risk taking behaviour among boys and men. The provision of health services is never gender neutral: it can exacerbate or alleviate gender inequities. This paper examines if and how the rebuilding and

\footnotetext{
* Correspondence: valerie.percival@carleton.ca

${ }^{1}$ Norman Paterson School of International Affairs, Carleton University, 1125 Colonel By Drive, Ottawa ON K1, Canada

Full list of author information is available at the end of the article
}

reform of health systems in conflict-affected and postconflict states is sensitive to its impact on gender.

Multilateral agencies and donors often see the postconflict period as a window of opportunity to undertake wide-ranging reforms of public sector institutions. For health experts, health sector projects in conflict affected states can improve the quality and accessibility of health care; increase the effectiveness and efficiency of the health system; ensure equity and expand social protection; and improve population health [1,2]. Donor resources are often readily available, impediments to change such as political disputes or vested interests may be temporarily absent, and the political will often exists to 'build back better' [3]. As a result, national governments are under pressure from 
multilateral agencies, such as the World Bank and the World Health Organisation (WHO), to undertake ambitious and wide-ranging health system reform measures [2]. We wanted to examine if reforms were sensitive to gender, and how such reforms could contribute to building gender equitable health systems.

To examine this issue, the Stockholm International Peace Research Institute (SIPRI) working group on gender (led by Prof Valerie Percival at Carleton University, Canada) and the ReBUILD research programme consortium which focuses on rebuilding health systems in post conflict contexts (led by the Liverpool School of Tropical Medicine, UK) partnered to explore the opportunities and challenges for building gender responsive health systems in post conflict contexts. The definition of "post-conflict" is fraught with ambiguity. As per the Uppsala Conflict Data Program (UCDP) conflict termination dataset, we examined countries that have experienced a victory by one side, a peace agreement, a cease-fire or an end to hostilities by other means [4]. The overall research project had two main phases. During the first phase, we explored if and how gender was integrated into the efforts to rebuild the health sector, examining humanitarian engagement in the immediate period following the cessation of hostilities, health reform in post-conflict contexts, and health systems literature more broadly. In the second phase, we examined four case studies to assess if and how gender had been integrated into efforts to rebuild the health system - Mozambique, Timor Leste, Sierra Leone and Northern Uganda.

The present literature review flows from Phase One of our research project, and represents an initial attempt to highlight the gaps, challenges and opportunities for building gender equity in post-conflict health reform. To set the context, we first outline the impact of conflict on gender and health incorporating recent debates on this subject. We then present the results of our review, summarizing the state of knowledge regarding the gendered impact of health system reform. We utilize the WHO building blocks to structure our analysis. The review concludes by highlighting the importance of gender equity from both a population health and socio-economic perspective. It concludes by outlining the key attributes of a gender equitable health system, and provides an agenda for future research.

\section{Methods}

The review was guided by the question "How gender sensitive is the reconstruction and reform of health systems in post conflict countries, and what factors need to be taken into consideration to build a gender equitable health system?" Given the novelty of this area of research, the review of the literature was narrative, rather than systematic. As stated by Baumeister "A narrative review is valuable ... when one is attempting to link together many studies on different topics, either for purposes of reinterpretation or interconnection. As such, narrative literature reviewing is a valuable theory building technique"([5], p.312).

Initially, we reviewed the literature on gender and health systems in conflict affected and post-conflict states. However, we were unable to evaluate many qualitative or quantitative studies on this subject because few have been published. The dearth of research on post conflict health reform in general, and gender dimensions of that process in particular, prompted us to expand our review to include the gendered impact of health system reform in developing states. Our initial goal of systematically evaluating the published literature on this subject gave way to our use of a narrative review to understand the gender dimensions of health systems, to provide guidance on why and how gender equity needs to be integrated into health system reconstruction and reform in post conflict states.

This process was iterative in nature - we reviewed peer reviewed and grey literature on health systems in postconflict and developing countries; gender and health in the humanitarian response; and the general literature on gender and health systems development. We also undertook case study research (not included in this review), which prompted additional areas of inquiry and further review of peer reviewed and grey literature. The WHO framework on health systems structured our inquiry. This framework identifies the key components of health systems as health service delivery/provision, human resources, health information systems, health system financing, medical products and technologies, and leadership and governance.

The iterative nature of this research facilitated the comprehensive nature of our review, and opened up additional areas of inquiry. We utilized Google Scholar, Google, PubMed and Scopus using the following terms: gender, gender equity, reproductive health, health reform, health system reform, and health structure reform. The initial review was supplemented with specific searches using google scholar and google for peer reviewed and grey literature in the following areas - general health reform (terms - health reform and gender), equity and gender (terms equity and equality with gender), medical products and technologies (terms - pharmaceuticals and gender, medical technologies and gender), and health system financing, including gender responsive budgeting (terms social insurance and gender, gender budgets). We also undertook a search that examined the link between gender equity and health outcomes (terms - gender equality and health) and gender and social-economic outcomes (terms - gender and social wellbeing, gender and peace). The majority of the studies were reviews, reflections, or frameworks of gender and health, with only a small number of the papers summarizing the results of either 
household surveys or interviews [only 6 papers out of 38 analysed in the first stage of the comprehensive review summarized original qualitative or quantitative studies; in the iterative stages of the review, were found no qualitative or quantitative studies]. As noted below, the paucity of qualitative or quantitative studies reflects the need for further investigation into this subject area.

\section{The context: gender, health and conflict Equity, equality, and gender and health}

Within the literature, the terms gender equality and gender equity are utilized almost interchangeably. However, this can be misleading: equality and equity are two distinct but related concepts. Equality refers to individuals objectively possessing the same rights and receiving the same benefits. However, a focus on equality overlooks the complex set of social and economic factors that result in unequal opportunities to be healthy and divergent health outcomes for various social groups - including women. The concept of equity acknowledges these differences, and recognizes that resources should be distributed - perhaps in an unequal manner - to benefit disadvantaged groups [6,7].

In all countries, men and women have differential health outcomes, with biology, individual behaviour, societal norms, environmental influences, and access to health care services all contributing to those differences [8]. Biologically, women are predisposed to live longer than men, yet they clearly suffer ill health as a consequence of pervasive discrimination, and the lack of value placed on their well being, whereas men's health outcomes are affected by their risk-taking behaviour and occupational hazards.

Structural inequalities rooted in gender norms have a pernicious impact on men and women's health, contributing to inequitable outcomes. The Women and Gender Equity Knowledge Network categorizes these inequities as discriminatory values, practices and behaviours; differential exposures and vulnerabilities to diseases, disabilities and injuries; biases in health services; and biases in health research [6].

How women and men, and boys and girls are valued, in particular how society views their relative worth, has a direct impact on health seeking behaviour and health outcomes. The impact of gender bias is evident throughout the lifespan with examples of sex-selection and boy-child bias during pregnancy and early life, early forced marriage, child birth practices that jeopardize women's health, and the failure to protect widow's rights [6]. Women's lower social status contributes to a lack of assertiveness, which undermines communication with health care providers [8].

Men and women also have different exposures and vulnerability to disease, disability and injuries. Some of this difference is determined primarily by biology, as the health risks related to reproduction differ greatly between men and women. However, other causes of differential vulnerability are socially determined, due to structural conditions that shape the ability of women and men to "avoid, respond to, cope and/or recover from exposures" $[6,8]$.

Health care services have a significant impact on equitable health outcomes. Evidence suggests that in some contexts, health care providers diagnose men and women very differently based on gender-role stereotyping. They overlook depression symptoms in men and cardiac symptoms in women [8].

Those women who work within the health system are remunerated far less, are less likely to advance into decision making positions and undertake a significant portion of unpaid work [6]. Women may face discrimination in accessing health care due to social, geographic or financial barriers [8].

Health inequities are also influenced by biases in health research. The research community often fails to recognize the interaction between gender, social factors and health outcomes. Despite the clear need for such information to shape programs, sex-disaggregated data is still not systematically collected $[6,9]$.

A recent analysis of Global Burden of Disease project data by Hawkes and Buse critiques global health programs for not addressing the burden of ill health among men. Their analysis shows that on a global level, the top ten contributors to disability-adjusted life-years (DALY) affect males disproportionally [10]. It is important to note that DALY indicators - particularly DALY indicators aggregated globally - can mask and miss important causes of ill health within particular groups in specific circumstances [11], for example, within conflict affected regions and among women of reproductive age. In addition, gender inequalities and gender norms may proscribe women and girls from engaging in behaviours and participating in experiences that lead to comparatively higher rates of diseases, injuries and causes of death among men. Moreover, the policies that would alleviate much of the burden of ill health among men, such as highway speed limits, workplace safety legislation, and gun control, are outside the remit of the health system, but this does not preclude health actors - both global and national - from developing strategic partnerships across sectors to advocate for such policies.

In our analysis of health systems literature, we looked for research on how health interventions affected men as well as women. Our review found that the literature on "gender" actually focused on the health of women, specifically maternal and reproductive health. Given the impact of conflict on men and boys, there is a need for more research on how health systems address - or do 
not address - the health needs of men and boys. Below we outline the gendered impact of conflict, and how gender is addressed in the overall post-conflict response.

\section{The impact of conflict on gender and health}

More men than women are injured or die from violence during wars due to their membership in armed groups [12]. For women, the breakdown in social norms as well as the absence of law and order increases the risk factors for sexual and gender-based violence (SGBV) from combatants as well as family and community members [13-15]. Due to their reproductive roles, women typically have a heightened vulnerability to ill health and a greater need for health services[16]. These vulnerabilities increase within situations of violent conflict. Research has demonstrated that rates of unsafe abortion and maternal mortality increase during intense phases of conflict [15].

The capacity of the national health system to respond to this greater need for health care services is compromised by conflict-induced disruptions - displacement of personnel, lack of funding, the interruption of supply chains, and the deterioration of or damage to health facilities [17]. Research shows that a comprehensive range of sexual and reproductive health services for adolescent girls and women may be unavailable. Even where health services are available, women may be unable to pay for these services [8]. Women may also face other obstacles to medical care due to insecure roads, cultural restrictions on travel, or responsibility for children and other family members [18].

Evaluating the health impact of these gender inequities is undermined by the lack of consensus regarding the most relevant indicators and how best to interpret these measures. Some authors have suggested a comprehensive mix of indicators including health status (maternal mortality as well as rates of sexual violence), health system data (insurance coverage, catastrophic expenditures, consultations), literacy and education, socio-economic status and employment, and political empowerment $[9,19]$. However, health information systems and other mechanisms to gather routine data are disrupted in conflictaffected environments and sex-disaggregated information is scarce. In addition, countries with the highest levels of gender inequality have poor quality data. Although quantitative indicators provide important information to inform analysis and guide programming, this analysis is incomplete without qualitative indicators derived from consultation with the affected population to understand meaning and context.

\section{Gender and post-conflict health engagement}

International engagement in the health sector during the immediate post-conflict period is largely through the delivery of humanitarian assistance. Elsewhere we have reviewed literature on gender in humanitarian interventions, with a focus on the critical analysis of Consolidated Appeals (CAPS). Our analysis of the CAPS highlights the overwhelming focus on sexual violence and maternal health, which characterizes the 'gender' component of humanitarian programming. While the gravity of sexual violence and the health risks of pregnancy and childbirth within conflict affected and post-conflict states warrant heightened resources, gender has an impact on health outcomes and health systems that extends beyond these two issues. Moreover, there is no evidence that these programs have been leveraged to enhance broader gender equality. This narrow focus could be limiting, falsely giving the impression that policymakers are adequately implementing gender sensitive programming [8]. Furthermore, programs and policies undertaken in the humanitarian period are path dependent, shaping future restructuring and reform initiatives within the health sector.

As the immediate post-war health crises fades, donors transition from humanitarian assistance to broader health system interventions. Significant resources are invested to build and reform health systems - to make them more efficient and effective. Within this context, we reviewed the literature on post-conflict engagement to examine if these reform efforts are gender sensitive.

\section{The review: gender and health system reform in the post-} conflict context and beyond

Identifying the gender impact of health system reform in post-conflict settings is impeded by the failure of health system researchers to meaningfully examine this question. We found no research that directly addressed the first component of our research question "How gender sensitive is the reconstruction and reform of health systems in post conflict countries?" Research into post-conflict health system reform has not sufficiently identified the differential health issues facing men and women, analysed how health systems respond to those differences, or provided recommendations for how to build gender equitable health systems [2,20-26].

As women and their children utilize health services more than men, reviews of post-conflict health reform assume that any improvements to the health system automatically promote gender equity. Reduction of maternal mortality is the indicator more often cited when referring to gender sensitive services. Recent studies on Afghanistan discuss how increasing the number of female health workers and the implementation of the Basic Package of Healthcare Services (BPHS) has contributed to increased pre- and antenatal visits to health facilities, behavioural change and a decrease in maternal mortality. [25,27] But these studies did not reflect on the integration of gender equity as a specific objective within the reconstruction of health care services. 
When we expanded our review to include health reform in developing states, we found that health system literature in general is characterized by the belief that gender is part of the broader social determinants of health, important in shaping health outcomes, but external to the health system [28]. Researchers and policy makers therefore assume that if health systems are strengthened, the health outcomes of both men and women will improve. There is no examination on how the operation and structure of health systems can impact on and improve equity.

Institutions are not neutral: they reflect the social context in which they are situated. Health systems can therefore contribute to gender inequities. Conversely, health systems can also contribute to improving gender equality and enhancing equitable outcomes between men and women. Our review of the literature reveals that with the exception of maternal health, research into health systems and their reform does not identify the differential health issues facing men and women, analyse how health systems respond, or provide prescriptions to ensure that they respond in a manner that contributes to gender equitable outcomes. To address the second component of our research question, "what factors need to be taken into consideration to build a gender equitable health system," we examined health system reforms in developing countries, using the WHO framework as an organizing principle.

WHO defines health systems as "all organizations, people and actions whose primary intent is to promote, restore or maintain health" [29]. In the past decade, researchers have identified the parameters of that system, assessed how the various components of the system relate to one another, and articulated the key goals and objectives of health systems and health system reform [29-32]. Our analysis of the impact of health system interventions on gender equity utilizes WHO's six building blocks of health systems to organize and structure our inquiry. These building blocks are health service delivery/provision; human resources; health information systems, health system financing, medical products and technologies, and leadership/governance. Under each building block, we provide a brief overview of the recent trends in health reform, along with evidence on how reform has addressed or influenced gender equity. We conclude by outlining how that component of a health system should integrate and address gender considerations. We begin our review with its 'first' building block - health service delivery.

\section{Health service delivery/provision}

Health system reform focuses on several aspects of health service delivery: the integration of services to ensure a more efficient provision of health care, the promotion of a basic or essential package of health services, and public versus private delivery of services, including management of private providers. Our review of the literature suggests that little research has been published on if and how these reforms consider their differential impact on men and women.

\section{Integration of service delivery}

Combining multiple health services can improve costeffectiveness, quality, and service efficiency through better coordination and pooling of resources. Health service integration can couple primary services with limited access to specialized care, and is more convenient for patients: they are more likely to access health care if they can combine multiple services, visit health centres less, and reduce transportation costs - which can be a significant access barrier for women [8]. Such integration can include community outreach services, which have been found to be more successful in ensuring that women with tuberculosis [33] and cataracts receive healthcare [8]. It also could ensure that health promotion is integrated more effectively into primary care - which would help address the burden of ill health among men.

There is evidence of some disadvantages to integration, including for gender. Vertical or stand-alone programs can more easily prioritize health issues for specific groups. In some contexts, providing separate programmes ensures that these services are effectively delivered, for example in a country where women and girls are not appropriately valued by communities or the state, where the provision of evidence based health services for women poses political challenges, or when male health indicators indicate interventions are required that target specific populations [8].

Integration requires providers to spread their resources over a wider range of health issues and can increase the complexity of health service delivery. Managers must integrate primary and specialist services, implement sophisticated planning, budgeting, and purchasing arrangements, and enhance the training of health staff. In Tanzania, health providers understood the rationale behind health service integration, but operationalizing integration policies was extremely challenging, given capacity shortfalls, even at the highest levels of government [34].

\section{Basic package of essential health services (BPHS)}

The 1993 World Development Report (WDR) recommended that one attractive option for cost-effective delivery of health services is contracting for the delivery of a basic package of health services [35]. Given the success of Afghanistan's contracting for services model, and the ability to include performance benchmarks, this model is becoming a favoured strategy in some post-conflict states [21]. Yet studies of the Afghanistan experience 
show that while improving health indicators for women, the BPHS did not sufficiently reflect on if and how to promote gender equity within the health system. Female health workers and the provision of primary health care services was a tool to reduce maternal mortality - not part of the effort to build a gender equitable health system or promote gender equity [25,27].

Despite international commitments to ensure women have access to comprehensive sexual and reproductive health services, most notably through the Millennium Development Goals, our research indicates that the BPHS does not always cover the provision of comprehensive reproductive health services, such as family planning, sufficient ante- and postnatal care including emergency obstetrics, and access to safe abortion [8]. In Ghana, for example, the BPHS covers only family planning [36]. While Nepal's BPHS includes family planning, basic safe motherhood interventions, and STI counselling, Nepal's health infrastructure and the capacity of health staff prohibited an expansion of services to newborn care, basic emergency obstetric care, and screening for cervical, breast and uterine cancer. The BPHS in Bangladesh includes very basic aspects of reproductive care, including maternal health and family planning, yet does not include treatment for violence against women and reproductive care for adolescents [37]. The same is true for Peru, despite the fact that an estimated $56.4 \%$ of violent crimes reported to the police are from women citing abuse from their male partners [38]. Evidence suggests that in postconflict states, donors have prioritized reproductive and maternal health, [21] yet whether this focus is retained after donor influence wanes has not been researched.

\section{Public and private provision of health services}

Most post-conflict states have a significant number of private providers participating within their health system. Policy makers face the challenge of regulating these providers to ensure quality services. Given human and financial resource shortfalls, some health system reforms work to integrate these providers into the formal system, specifically through public-private partnerships. In the area of sexual and reproductive health, such partnerships have increased the provision of health services, particularly in countries or communities where public policy supports regressive policies that do not protect women's rights to comprehensive sexual and reproductive health services [8]. The embrace of the private sector in health reform efforts generates strong reactions. Their positive or negative contribution towards universal access to health care services in general, and the impact on gender equity in particular, is often context dependent and requires more research.

In summary, equitable and effective health services must be able to address the most urgent health care needs of men and women within a given context and across their life spans with evidence based interventions. How health services are structured influences their ability to achieve that objective. Planning processes in post conflict contexts need to carefully consider the needs of all population groups. Care must be taken when implementing integration, BPHS, and the promotion of public/private partnerships to ensure that these reforms improve rather than undermine gender equity.

\section{Human resources}

Addressing human resource shortfalls has been central to health sector reform in post-conflict and developing regions. However, little attention has been paid to gender in the process of workforce restructuring [39]. While women comprise the majority of employees in the formal health system, they are less likely to hold senior professional, managerial and policy-making roles [8]. Women remain concentrated in service delivery roles, including as nurses, midwifes, and community health workers which receive less pay and respect than male-dominated roles [8]. In many developing countries, women have been more heavily affected than men by downsizing and by reforms to pay structures and employment conditions. Research also shows that women are given fewer opportunities to retrain for new positions or to advance professionally in their careers [40]. Despite the preference for physicians of the same sex, [8] we found no evidence that health reforms prioritize affirmative action in the training of physicians.

Health sector reforms have also failed to consider gender while developing and implementing recruitment, retention and career advancement strategies [41]. Our review found that little consideration has been paid to the different family roles and obligations of female versus male workers and how these may impact their employment needs and preferences $[8,41]$. This is due in part to the failure to consult key stakeholders, including health care providers, in the design of human resource reforms. Women in particular have been largely absent during human resource planning processes, due to their lack of representation at higher decision-making levels [39].

In recent years, there has been increasing interest in and revitalisation of community health worker (CHW) programmes as a way to strengthen health systems and meet equity goals. In some contexts $\mathrm{CHWs}$ are remunerated and seen as part of the health system and in other contexts they are volunteers. In some countries this cadre is all female (for example, Health Extension Workers in Ethiopia and Lady Health Workers (LHWs) in Pakistan) and in others it is mixed, with women making up the minority of CHWs in some contexts. Evidence from Pakistan reveals how LHWs must operate within the same gender systems that cause inequitable health outcomes for women; the interplay of gender, 
class and hierarchy means that LHWs, like the women they serve, are likely to be marginalized and disadvantaged by the male dominated context within which they live [42]. There is a need to better understand how gender shapes the opportunities and challenges faced by CHWs who in many contexts provide a vital interface between health systems and communities.

Gender inequities are also widespread among volunteer health workers [40]. Female household and community members provide a large majority of the non-institutional and unpaid care in developing regions. Most notably, women tend to be targeted specifically for unpaid community health work [39]. For example, community health programs in Peru, including immunization and nutritional campaigns, have relied heavily on women's voluntary labour for their success [38].

In summary, a gender equitable health system would promote equal opportunities for both male and female health workers across all cadres, including community health workers and volunteers. This is particularly critical in post-conflict contexts, where opportunities exist to break down gender barriers and stereotypes. The development of human resource strategies, a key area of action in health sector reform in post conflict contexts, must address gender disparities in advancement, planning, retention, supervision and remuneration across all areas of the health workforce.

\section{Health information systems}

WHO states that "health systems should ensure the production, analysis, dissemination and use of reliable and timely information on health determinants, health system performance and health status" [28]. Having information broken down by sex, age, and other socioeconomic variables is crucial to promoting equity - including gender equity - in health systems [43]. Just having health outcome data disaggregated by sex is not enough - health information needs to determine if and how gender inequities may influence those outcomes [8]. This is particularly the case in post-conflict contexts, where the conflict may have altered population patterns and health trends. However, health information is not always available in a manner that provides policy makers with the tools to identify gender differences in health, compare across contexts, [44] analyse the reasons for those differences, and respond accordingly.

In Bangladesh, health decision-makers were constrained by limited data and the fact that existing planning tools and indicators were not gender sensitive [45]. Similar problems were identified in a study on health reform in China. While China's health system collected sex-disaggregated information to map specific diseases among men and women, data that outlined trends in service use and treatment patterns by gender and identified gender-specific behaviours influencing health outcomes was not available. Sex-disaggregated health data was also lacking on children, and more systematic data collection was needed to discern the gendered health consequences of labour restructuring [46].

In addition to identifying the differing health priorities of men and women, appropriate indicators are needed to measure the impact of health reform on gender equity [47]. However, integrating gender equity considerations into the monitoring and evaluation of health sector reform has proved challenging [40]. In part, this is due to a lack of agreement on the best proxy measures for gender equity in health sector reform. Health indicators tend to be primarily biomedical, based at the population level, and insufficiently disaggregated. The Pan-American Health Organization (PAHO) Health Sector Initiative, for instance, has indicators on health care coverage, distribution of resources, access and resource utilization, yet few of these indicators consider specific gender-related health needs [48]. A volume of studies, Performance Measurement for Health Systems, highlights the challenge of measuring health system performance, yet does not integrate gender into its analysis [49]. Moreover, such indicators need to be practical - overstretched health workers cannot be tasked with the collection of reams of data. More discussion is needed on what indicators are the most appropriate, and how these indicators can be easily gathered in low-resource settings.

In summary, in post-conflict contexts health information systems should be tailored to facilitate the rapid collection, collation and use of easily accessible information to support the evaluation and adaption of services to meet the needs of different groups.

\section{Health system financing}

Health financing plays a large role in determining the availability of health care, who can access care, and the degree of financial protection provided to individuals [50]. Research shows that due to women's health needs and their responsibility for childcare, women incur more out of pocket expenditure for healthcare than men, that such expenditure poses a more significant financial burden for women given their economic status, and acts as a barrier to access due to their inability to pay or the unwillingness of their families to pay for health services for women $[8,33]$. Given the precarious economic situation of most post-conflict states, as well as the path dependent nature of health reform, initiating effective, context-appropriate and equitable financing mechanisms as part of postconflict reconstruction is critical.

Although varying according to context, in 2012 experts estimated that the annual cost of a minimum primary health care package in the developing world was approximately USD 50-60 per person [51]. There are 
many different mechanisms for generating health care revenue, each with implications for access and availability of care. However, as our review of the literature indicates, analyses of health care financing methods surprisingly pays little attention to how these financing reforms impact on the differential health needs of women and men. The WHO's 2010 World Health Report examines how health care financing can further the objective of universal access to a basic package of health services, but did not specifically address the issue of gender equity [52].

All health care systems receive a degree of support from the state budget, funded by revenue gained through various taxes. Through the Abuja Declaration, developing countries have a target of dedicating 15 percent of their total budget to health; however even if they met that target, many would be unable to generate sufficient revenue to provide universal access to health care services [51]. Several options exist to increase funding for the health sector. Donors can provide direct budgetary support, but countries are then subject to the fickleness of donor aid, which ebbs and flows based on donors' policy choices rather than developing country needs. Direct budgetary support without sufficient oversight capacity is susceptible to corruption $[2,21]$. To ensure accountability, donors often impose rigorous reporting requirements that can be burdensome for developing countries [52]. For more sustainable domestic sources of funding, policy makers can introduce revenue generating reforms including user fees, social and private insurance schemes, and community financing. We begin our review with a brief examination of the gender implications of health financing through general government revenues and then turn to user fees, social health insurance and private insurance.

\section{Government budget (Taxation, supplemented by donor's direct budgetary support)}

Health systems throughout the world are completely or partially financed through tax revenue collected by government. This method of financing has several advantages. It can ensure a larger risk pool, and depending on how providers are reimbursed for their services, can be more easily managed in lower capacity contexts. The ability of low-capacity states, such as those emerging from violent conflict, to oversee more complex financing programs, such as social insurance (see below), and safeguard them from corruption, can be limited due to the lack of skilled and sufficiently reimbursed public servants.

Health systems reliant on allocations from the general budget count on a broader source of funds: revenue can be gathered through direct and indirect taxes, including consumption taxes and custom duties, increasing the size of the risk-pool and the funds available for the health system. Recent examples such as Rwanda and Kyrgyzstan, demonstrate how governments can effectively utilize central budgetary support to supplement direct health care contributions and expand health coverage [53]. Research examining South Africa, Ghana and Tanzania shows that "all public sources of finance were progressive in all three countries (with the sole exception of indirect taxes in South Africa), by contrast with a common perception that public financing sources can be regressive because richer groups are better able to avoid paying tax" [54].

Reliance on government revenues can therefore contribute to equity of access among lower income groups; this benefits women who constitute a significant share of the poor and those working in the informal sector. However, there are pitfalls to an over-reliance on government financing. Budgetary allocations are subject to the decisions of politicians, who may not prioritize health care in general, or women's health needs in particular. In traditional or religiously conservative societies, health care funding may exclude important services such as sexual and reproductive health and services for women and adolescent girls.

\section{User fees}

User fees, adopted on a formal and an informal basis, are a form of health financing often employed in postconflict settings [21,22]. Introduction of user fees for health services was a strategy championed by the 1987 Bamako Initiative and implemented in many African countries in the 1980-90s [47]. User fees can raise unrestricted funds for health delivery, with a portion of these fees staying at the local level. Formal fees may be implemented to fills gaps in public health budgets [21]. In addition, informal fees (or under the table payments) may be charged by health workers during and in the aftermath of conflict to cover unpaid salaries.

The aggregation of these fees can easily become 'catastrophic' in conflict and post-conflict settings [22]. A 2010 DFID Briefing Paper on promoting non-discrimination and effective engagement in conflict-affected and fragile situations warns that user fees can restrict the poorest and most marginalised communities from access to services [55]. User fees are both regressive and inequitable individuals are less inclined to use services that require out-of-pocket payments, and these fees require the poorest people to pay a larger proportion of their income for care [40].

Women make up the majority of the poor in developing regions, and user fees have been shown to decrease women's use of all health services. Reproductive health care is the most price elastic [40]. User fees implemented in Nigeria, Tanzania and Zimbabwe were correlated with a decline in the use of maternal and child health services and an increase in morbidity rates among delivering mothers and their babies [41]. Similar results have occurred with the introduction of user fees in India. While cases of untreated illness were common among 
the poor for common health services, the situation was worse among women and girls [56]. Overall, user fees have resulted in significant health consequences in developing regions, including untreated morbidity, reduced access to care, long-term impoverishment and improper use of drugs as a result of self-medication- such as the use of contra-indicated drugs for pregnant women [50].

Although exemptions to user fees have been put in place in many countries, these exemptions are applied inconsistently at the discretion of the health providers without clear guidelines to sufficiently assess patients' financial means [40]. Patients are often not informed of their right to ask for a fee waiver. Exemptions to user fees in African countries tend to benefit wealthier groups such as civil servants instead of the poor. In Ghana, for example, only 1 percent of user fee exemptions went to patients while 77 percent went to health service staff [57].

\section{Social health insurance}

Social insurance schemes are composed of individuals employed in the formal sector who establish risk pools in the event of sickness. Because they are tied to formal employment, social insurance schemes may serve only a proportion of the population, often those who are economically advantaged. In Tanzania, for example, the National Health Insurance Fund covered only 300,000 civil servants in 2004 from a total population of 32 million. The low coverage rate is particularly problematic for sub-Saharan Africa, a region where less than $10 \%$ of the population are employed in the formal economy [58].

In the absence of a robust tax base, social insurance schemes may provide the most equitable basis for health care financing [50], and many post conflict settings aspire to introduce social insurance in the future. However, from a gender perspective, social insurance may be inequitable as fewer women are employed in the formal economy. While women can be covered as a dependant under their husbands' social insurance scheme, this type of insurance would not be available to unmarried or widowed women who are employed in informal or unpaid work, to women in polygamous relationships, or to their dependants [59]. There are also countries such as Chile that allow women to be covered as part of their husband's insurance, but do not extend the same benefit to husbands under the conditions of insurance offered to women [60].

\section{Private insurance}

Unregulated private health insurance can create discriminatory practices and inadequate coverage. Women have a greater need for health services than men; therefore coverage based on a calculation of risk would have a negative effect on women. For the same reason, private insurance also tends to involve greater out-of-pocket expenditures and higher private insurance premiums for women [43]. Private insurance often will exclude beneficiaries due to pre-existing health conditions, and may not cover all sexual and reproductive health services [8]. In Chile, for example, private health insurance discriminates against women by charging women at least twice as much as men in the same age bracket based on the expectation they will incur more medical expenses [60]. Additionally, like social insurance schemes, private insurance is often linked to employment, which can burden women disproportionately due to their greater representation in informal or unpaid work.

Community financing schemes, also known as Mutual Health Insurance, are another common strategy for financing health care in developing regions. With this approach, local communities risk-pool at the community level, setting aside resources to allocate towards health services. One form that has been introduced in several subSaharan African countries involves community-based voluntary pre-payment schemes [59]. Such schemes have been designed with features to promote inclusion such as paying premiums in instalments, issuing exemptions for those unable to pay, and flexible payment times for those with unsteady or seasonal income.

Assessments of these schemes reveal a number of shortfalls with implementation and its impact on gender equity. First, community-based schemes tend to face low participation rates because of the inability of the poor and marginalized, particularly women, to pay premiums [8]. In Tanzania, for example, only 3-10 percent of community members in different districts were registered with available schemes after a five-year period [59]. From a gender equity point of view, low membership numbers in community-based schemes means a smaller risk pool, which disproportionately affects women due to their inability to pay and higher health needs. Moreover, management of these schemes is usually not gender equitable. In Mali, for example, only $12.9 \%$ of health committee members are women, and the majority of them hold minor roles and few responsibilities [47].

\section{Gender responsive budgets}

Gender responsive budgets are a tool to analyse governmental budgets from the perspective of gender equality and the fulfilment of women's rights. These budgets analyse the gender-differential impact of revenue-generation and allocation of national country budgets as well as Official Development Assistance [61]. In Mozambique, UNICEF has collaborated with the government to promote gender responsive budgeting in three priority areas: violence against women, maternal mortality, and HIV/AIDS with a number of positive outcomes. Funding for programmes addressing violence against women have been strengthened and used to create facilities for survivors 
of domestic violence in police stations in all 129 districts of Mozambique [62]. However, analysts caution that the application of gender responsive budgeting has been restricted to maternal health, sexual violence, and HIV/AIDS, without an application to broader health programming [63].

In summary, more gender equitable health financing mechanisms are critically important in post-conflict contexts. Health financing must include those working in the informal sector; be publicly financed with little or no additional premiums; enrol entire households; include comprehensive sexual and reproductive health services, and prohibit exclusion due to pre-existing conditions [8].

\section{Medical products and technologies}

Our review showed that more research is needed in this area, as women and men's access to medical products and technologies is influenced by gender and by differing biological responses to pharmaceuticals.

The pharmaceutical sector is complex to manage with informal markets and counterfeit medicines complicating efforts to rebuild and reform this component of the health system. In a review of pharmaceutical systems in four conflict-affected states, Kohler et al., highlighted the importance of the informal sector to pharmaceutical supply, as well as the reliance on multilateral actors, but neglected to examine the gender dimensions of the availability and access to medical products and technologies [64].

Financial and socio-cultural constraints may reduce women's access to particular medical products and technologies, with limited access to and availability of comprehensive reproductive health pharmaceuticals and medical products [8]. This gender bias extends beyond sexual and reproductive health. Biases may begin at a young age with gender differentials in resources allocated to medical products for boys and girls. In West Bengal in India, a study found that parents were more likely to give boys home fluids and oral rehydration solutions for diarrhoea, and that more money was spent per episode on treatments for boys [65]. A study in Benin found that while women were more likely than men to purchase Permethrin-Impregnated Bednets (PIBs), these purchases were constrained by their considerably lower incomes [66].

Sex differences also influence pharmaceutical efficacy. Due to the hormonal changes related to reproduction, drug treatment is more complex in women. Women and girls react differently to drugs and vaccines than men and boys, yet these differences have not been sufficiently studied, nor are they taken into account in prescribing dosages [8].

In addition, gender acts as a barrier to treatment. Women are more likely than men to interrupt long-term pharmaceutical treatment for chronic diseases because they are financially unable to continue treatment or they "do not feel entitled to spend money on themselves" [8]. Research suggests that diagnostic procedures for tuberculosis (TB) present specific barriers for women. The diagnosis pathway for TB entails several steps: if a person experiences a cough for more than three weeks they may be given antibiotics; if there is no response within three weeks they must return to the health centre for referral (usually to hospital or specialist facility) where they must submit three sputum samples over two days. As a result, patients stay overnight at or near the facility and must return to the hospital to collect results. For women whose movements are already restricted due to childcare responsibilities or socio-cultural norms regarding travel outside of the community, these requirements present considerable barriers to diagnosis, and therefore to curative therapy [33]. More men than women are diagnosed with TB at an average ratio of $1.8: 1$ (between 1.2 and 2.2:1) [67]. However studies have shown lower case detection rates amongst women than men in 'passive case finding' - e.g. India and Vietnam $[68,69]$. Studies in Thailand, Vietnam and China have also found differences in the time taken to diagnose women and men with TB even once they entered the formal health-care system [70-72].

In contrast, in most countries more women than men receive antiretroviral therapy (ART) to treat HIV/AIDS, a disparity that is particularly pronounced in generalized epidemics [73]. This has been linked to a number of gender issues. Men may be reluctant to seek care as a 'matter of pride' while women may attend maternal health services and HIV services in order to behave as 'good' mothers and wives [74]. Programmes to prevent mother-to-child transmission may facilitate the entry of HIV-positive women into treatment [73]. However, women continue to have less control over technologies such as male condom use - that could protect them from becoming infected with HIV.

In summary, while medical products and technologies are often perceived to be gender neutral, gender norms influence access to those drugs as well as their utilization. In post-conflict settings, there is a need to strategically plan how to support access and adherence to different medical products and technologies for different groups of women and men.

\section{Leadership and governance}

Government decisions facilitate or impede the effective functioning of the health system. Male-dominated Ministries of Health have traditionally defined national priorities for health care in developing countries in a top-down manner. Women in most countries are under-represented in decision-making bodies at all levels, including the local level [50]. The post-conflict context, where the international community pushes for equitable political representation of 
women, presents an important opportunity for the health system to promote gender equity. Promoting women in senior levels in the health sector could have important reverberations throughout the health system: evidence indicates that when management does not include sufficient women or gender sensitive tools, women's health needs will not be reflected in local health priorities, and financial and human resources will not be allocated accordingly [75].

Many health reforms decentralize responsibility for the governance of health services to the local level, with the hope that this will enhance the responsiveness of the health system. However, this can have a negative impact on gender equity. Evidence suggests that in developing regions, decentralization is often undertaken without the requisite human, institutional and financial resources to ensure the provision of affordable, accessible and equitable health services [21,50]. For example, Zimbabwe had the highest contraceptive-use rates in Africa in the 1990s. The national program received significant resources, had a strong logistics system, and undertook coordination with health districts for community distribution. After decentralization, the success of the program was not replicated at the district level. Local providers had little experience with family planning, and were required to provide this service along with numerous other health services [47].

Particularly in rural areas, where health decisions are predominantly made by men, decentralization can also support more conservative agendas in reproductive health [43]. In the Philippines, the influence of the Catholic church at the local level resulted in regional bans on the provision of contraceptives despite progressive national reproductive health policies [37]. Not only can decentralization neglect women's health needs, the process can reinforce patriarchal policies in local communities by reinforcing men's community decision-making power [38].

In summary, more input is needed from gender advocates to ensure that gender-specific health needs are considered in the governance of health systems. This is particularly necessary in post-conflict settings, where greater opportunities for social reform - such as promoting the advancement of women to health leadership positions - often exist.

\section{Discussion}

Evidence suggests that health sector reform in postconflict contexts, as well as in developing countries, has been largely blind to its impact on gender equity: it has failed to sufficiently identify the distinct health needs and experiences of men and women, analyse the factors that contribute to that difference, and respond accordingly. Without such an analysis, health system reform can miss important opportunities to promote gender equity, and also negatively impact on women's (and men's) health and access. Women are overrepresented in lower paid and informal care-giving roles, and have been disproportionately affected by human resource policies that fail to consider their professional needs in employment contracts, incentives, and career advancement opportunities. Health information systems are weak and do not routinely collect specific health data that would monitor and measure the impact of health reform efforts on gender equity. Financing mechanisms tend to negatively affect women more than men, as few are eligible for employment-based health insurance, and their relatively lower status in society means they have less access to financial resources to pay for health care.

Particularly problematic in both post-conflict and developing country contexts is the absence of a clear definition of a gender equitable health system. Without an aspirational objective in mind, it is very difficult to measure progress. How can we assess if a health system fails to be gender equitable if we have not identified the attributes of such a system? How can post-conflict health reforms aim to 'build back better' without such basic guidance?

Based on the research undertaken as part of this literature review, we propose a definition of a gender equitable health system as a health system that:

- Provides health care services that address the most urgent health care needs of men and women across the life span in an appropriate manner;

- Ensures men and women across the life span are able to access and utilize those services unimpeded by social, geographic and financial barriers;

- Produces relevant, sex disaggregated health information that informs policy;

- Ensures equitable health outcomes among women and men, and across age groups; and,

- Provides equal opportunities for male and female health professionals working within the health system.

\section{The importance of gender equitable health systems}

There are two key reasons to build gender equitable health systems in post-conflict contexts. First, ensuring that health system reform builds gender equitable systems will improve the operation and responsiveness of health systems with the goal of improving health outcomes. And second, emerging research suggests that gender equality facilitates broader social and economic wellbeing, as well as stability. Ensuring that the reconstruction and reform of health systems creates gender equitable systems can facilitate gender equality.

\section{The impact on health}

Health systems literature assumes that by simply reforming and strengthening health institutions, better performing 
health systems will contribute to better health outcomes for both men and women. However, our review of health systems literature demonstrates that this relationship is not straightforward: health systems reflect their social context. In the absence of gender equality, and without careful attention to how health system reforms will differentially affect the health of men and women, health systems can replicate the gender inequality that exists in that particular society. While it has been challenging to find evidence that discerns the relationship between gender equality and health outcomes, [76] women and children are clearly healthier in societies where their rights are protected [77].

Do health systems with the attributes identified as 'gender equitable' better respond to the differential health needs of women and men and lead to improved health outcomes? Moreover, what aspects of a 'gender equitable' health system are most important, and how can they best be built? Answering these questions requires further study.

\section{The impact on broader social wellbeing and gender equality}

Health systems mirror their context, reflecting social inequalities throughout the delivery and provision of health care services. Yet health sector interventions can also contribute to social change. Could health system reconstruction and reform, particularly the effort to build gender equitable health systems, contribute to gender equality and have cascade effects throughout society as it works to rebuild after war? Such efforts could be particularly important given research on the role that gender equality plays in contributing to more peaceful and prosperous societies.

Recent research suggests that the damage done by gender hierarchies and the resulting inequalities extends far beyond individual women and their families, impacting on broader social and economic indicators. Analysis by the World Economic Forum highlights that gender equality is strongly correlated with economic competitiveness, GDP per capita, and human development. Moreover, those states with higher levels of women's social and economic rights consistently exhibit lower levels of corruption [78]. "While correlation does not prove causality, it is consistent with the theory and mounting evidence that empowering women means a more efficient use of a nation's human talent endowment and that reducing gender inequality enhances productivity and economic growth" ([79], p.27).

Cross-national quantitative analysis also demonstrates that states with higher levels of gender equity exhibit lower levels of violence in international crises, and are less likely to initiate the use of force. States with higher levels of gender inequality are also more prone to intrastate conflict or civil war [80]. Moreover, states with higher levels of gender equality, including social, economic and political equality, are less likely to rely on military force to settle disputes [81]. Women's empowerment also plays a role contributing to stability within conflict-affected states. Research has found that the status of women in society can be an important determinant of successful international efforts to build peace within conflict-affected societies $[82,83]$.

While more research is needed into how gender roles contribute to peacebuilding, researchers hypothesize that societies with a higher status for women are characterized by greater social capacity and a larger network of informal institutions. Women's networks can bridge or transcend ethnic and clan divisions, which helps contribute to greater social resilience against conflict $[82,83]$. Notably, initiatives by women to address health and social concerns in communities can be instrumental to bridge divisions, and build local communities' support for peacebuilding process. While sceptics may argue that women's empowerment is itself caused by greater economic and social development, researchers find that "women's empowerment seems to be a separate dimension of social development that cannot fully be accounted for by economic or even political factors alone" ([83], p. 510).

\section{Conclusion}

This narrative literature review reveals that health systems research has not provided policy makers with clear guidance on how the functioning of health systems is impacted by gender inequalities and how strengthening health systems can improve gender equity. There is little clarity on what a gender equitable health system would look like nor have key indicators been identified to measure how health systems could promote such equity. Without a definition of a gender equitable health system, those planning and funding the reconstruction and rebuilding of health systems in post-conflict context have no guidance or incentives to implement gender sensitive reforms. Given the opportunities presented by international engagement in the health sector in the post-conflict period, and the importance of gender equality to broader social well being, it is time for policy makers and advocates to recognize the opportunities present in health system reform. By identifying the attributes of a gender equitable health system, and implementing those attributes within health system engagement, health system reform can contribute to a foundation of gender equality.

\section{Abbreviations}

ART: Anti-Retroviral Treatment; BPHS: Basic Package of Health Services; CAPS: Consolidated Appeals Process; CHW: Community Health Workers; DALY: Disability Adjusted Life Year; LHW: Lady Health Workers; PAHO:

Pan-American Health Organization; PIBs: Permethrin-Impregnated Bednets; SIPRI: Stockholm International Peace Research Institute; SGBV: Sexual and Gender Based Violence; TB: Tuberculosis; UCDP: Uppsala Conflict Data Program; WDR: World Development Report; WHO: World Health Organization. 


\section{Competing interests}

The authors declare that they have no competing interests.

\section{Authors' contribution}

VP led the study, formulated the research questions, supervised the review, undertook additional research for the review, and was the primary author of the manuscript. ER undertook additional research for the review and contributed to the writing of the manuscript. TM undertook the first review of literature. ST proposed the study and provided input and advice on all stages of the research. All authors read and approved the final manuscript.

\section{Acknowledgements}

With thanks to the Stockholm International Peace Research Institute (SIPRI) for creating and funding the work of the Gender and Ethnicity Working Group. With thanks also to the ReBUILD project: re-building health systems in post conflict states in Cambodia, Sierra Leone, Uganda and Zimbabwe, funded by the UK Department for International Development (DFID). ReBUILD (see http://www.rebuildconsortium.com) is a consortium of six partners: Liverpool School of Tropical Medicine; Institute for International Health and Development, Queen Margaret University, Edinburgh; Cambodia Development Resource Institute; College of Medicine and Allied Health Sciences, Sierra Leone; School of Public Health, Makerere University, Uganda and the Biomedical Research and Training Institute, Zimbabwe. This manuscript is part of the 'Filling the Void: Health systems in fragile and conflict affected states' thematic series.

\section{Author details}

${ }^{1}$ Norman Paterson School of International Affairs, Carleton University, 1125 Colonel By Drive, Ottawa ON K1, Canada. ${ }^{2}$ Department of International Public Health, Liverpool School of Tropical Medicine, Pembroke Place, Liverpool L3 5QA, UK. ${ }^{3}$ Department of Global Health and Development, London School of Hygiene and Tropical Medicine, London, UK.

Received: 17 June 2014 Accepted: 17 September 2014

Published: 22 October 2014

\section{References}

1. Pavignani E: Analysing Disrupted Health Sectors: A Toolkit. Geneva: World Health Organization; 2005.

2. Percival V, Sondorp E: A case study of health sector reform in Kosovo. Confl Heal 2010, 4:7-14.

3. Collier P: Development in dangerous places. Boston Rev 2009, July/August.

4. Kreutz J: How and when armed conflicts end: introducing the UCDP conflict termination dataset. J Peace Res 2010, 47:243-250.

5. Baumeister $R$, Leary $M$, Cronin $P$ : Writing narrative literature reviews. Rev Gen Psychol 1997, 1:311-320.

6. Sen G, Oslin P: Gender inequity in health: why it exists and how we can change it. Global Public Health 2008, 3:1-12.

7. Braveman P, Gruskin S: Defining equity in health. J Epidemiol Community Health 2003, 57:254-258.

8. WHO: Gender, Women and Primary Health Care Renewal: A Discussion Paper. Geneva: World Health Organization; 2010.

9. Diaz-Granados N, Blythe Pitzul K, Dorado L, Wang F, McDermott S, Rondon M, Posada-Villa J, Saavedra J, Torres Y, Des Meules M, Stewart D: Monitoring gender equity in health using gender senstitive indicators: a cross-national study. J Women's Health 2011, 20:145-153.

10. Hawkes S, Buse K: Gender and global health: evidence, policy, and inconvenient truths. Lancet 2013, 381:1783-1787.

11. Anand S, Hanson K: Disability-adjusted life years: a critical review. J Health Econ 1997, 16(6):685-702.

12. HSRP: Human Security Report 2005. Oxford: Oxford University Press; 2005.

13. Enloe C: Maneuvers: The International Politics of Militarizing women's Lifes. Berkely: University of California Press; 2000.

14. HSRP: Human Security Report 2012: Sexual Violence, Education and War Beyond the Mainstream Narrative. Vancouver: Human Security Press; 2012.

15. McGinn T, Casey S, Purdin S, Marsh M: Reproductive health for conflict-affected people: policies, research and programmes. HPN Network Paper 2004, 45:30.

16. McGinn T: Reproductive Health of War-Affected Populations: What do we know? Int Fam Plan Perspect 2000, 26:174-180.

17. Salama P, Spiegel P, Talley L, Waldman R: Lessons Learned from Complex Emergencies over the Past Decade. Lancet 2004, 364:1801-1813.
18. WHO: Reproductive Health During Conflict and Displacement. Geneva: World Health Organization; 2000.

19. Gill R, Stewart D: Relevance of gender-sensitive policies and general health indicators to compare the status of south Asian Women's health. Women's Health Issues 2011, 21:12-18.

20. Kruk M, Freedman L, Anglin G, Waldman R: Rebuilding health systems to improve health and promote statebuilding in post-conflict countries: A theoretical framework and research agenda. Soc Sci Med 2010, 70:89-97.

21. Witter S: Health financing in fragile and post-conflict states: What do we know and what are the gaps? Soc Sci Med 2012, 75:2370-2377.

22. Bornemisza O, Ranson M, Poletti TM, Sondorp E: Promoting health equity in conflict-affected fragile states. Soc Sci Med 2010, 70:80-88.

23. Alonso A, Brugha R: Rehabilitating the Health System After Conflict in East Timor: A Shift from NGO to Government Leadership. Oxford: Oxford University Press in Association with the London School of Hygiene and Tropical Medicine; 2006.

24. Tulloch J, Saadah F, Araujo RMD, Jesus RP, Lobo S, Hemming I, Nassim J, Morris I: Initial Steps in Rebuilding the Health Sector in East Timor. Washington: The National Academies Press; 2003.

25. Newbrander W, Lckx P, Feroz F, Stanekzai H: Afghanistan's basic package of health services: its development and effects on rebuilding the health system. Global Public Health 2014, 9(Suppl 1):S6-S28.

26. Newbrander W, Yoder R, Debevoise AB: Rebuilding health systems in post-conflict countries: estimating the costs of basic services. Int J Health Plann Manag 2007, 22:319-336.

27. Newbrander W, Natiq K, Shahim S, Hamid N, Skena NB: Barriers to appropriate care for mothers and infants during the perinatal period in rural Afghanistan: a qualitative assessment. Global Public Health 2013, $8: 10$.

28. WHO: Monitoring the Building Blocks of Health Systems: A Handbook of Indicators and Their Measurement Strategies. Geneva: World Health Organization; 2010.

29. WHO: Strengthening Health Systems To Improve Health Outcomes: WHO's Framework for Action. Geneva: World Health Organization; 2007.

30. DeSavigny D, Adam T: Systems Thinking for Health Systems Strengthening Geneva: World Health Organization; 2009.

31. Murray $C J L$, Frenk J: A framework for assessing the performance of health systems. Bull World Health Organ 2000, 78:717-731.

32. Roberts M, Hsiao W, Berman P, Reich M: Getting Health Reform Right: A Guide to Improving Performance and Equity. Oxford: Oxford University Press; 2004.

33. Needham DM, Foster SD, Tomlinson G, Godfrey-Faussett P: Socio-economic, gender and health services factors affecting disnostic delay for tuberculosis patients in urban Zambia. Trop Med Int Health 2001, 6:256-259.

34. Oliff $M, A l$ E: Integrating reproductive health services in a reforming health sector: the case of Tanzania. Reprod Health Matters 2003, 11:37-48.

35. Bank W: World Development Report: Investing in Health. World Bank: Washington; 1993.

36. Dmytraczenko T: Health Sector Reform: How it Affects Reproductive Health Population Reference Bureau: Washington; 2003.

37. Murthy R, Klugman B: Service accountability and community participation in the context of health sector reforms in Asia: implications for sexual and reproductive health services. Health Policy Planning 2004, 19:i78-i86.

38. Ewig C: Global Processes, Local Consequences: Gender Equity and Health Sector Reform in Peru. Oxford: Oxford University Press; 2006.

39. Standing $\mathrm{H}$ : Gender - a missing dimension in human resource policy and planning for health reforms. Health Resour Health Dev J 2000, 4:16.

40. Doyal L: Gender and Health Sector Reform: A Literature Review and Report from a Workshop at Forum 7. Geneva: Global Forum for Health Research; 2003.

41. Standing H: New Trends in Financing for Health Care: What Impact on Reproductive Health? Sussex: Institute of Development Studies; 2002.

42. Mumtaz Z, Salway S, Waseem M, Umer N: Gender-based barriers to primary health care provision in Pakistan: the experience of female providers. Health Policy Planning 2003, 18:261-269.

43. PAHO: Guide for Analysis and Monitoring of Gender Equity in Health Policies. Washington: Pan American Health Organization; 2007.

44. Diaz-Granados N, Pitzul KB, Dorado LM, Want F, McDermott S, Rondon MB, Posada-Villa J, Saavedra J, Torres Y, Meules MD, Stewart DE: Monitoring gender equity in health using gender-sensitive indicators: a cross-national study. J Women's Health 2011, 20:145-153.

45. Roanaq J: Restructuring the health system: Experiences of advocates for gender equity in Bangladesh. Reprod Health Matters 2003, 11:183-191. 
46. Chen L, Standing H: Gender equity in transitional China's healthcare reform policies. Fem Econ 2007, 13:189-212.

47. Onyango C: Gender and Equity in Health Sector Reform: A Review of the Literature. Washington: Pan-American Health Organization; 2001.

48. PAHO: Methodology for Monitoring and Evaluation of Health Sector Reform in Latin America and the Carribean. Washington: Pan American Health Organization; 1998.

49. Smith PC, Mossialos E, Papanicolas I, Leatherman S: Performance Measurement for Health System Improvement. Cambridge: Cambridge University Press; 2009.

50. Europe WHO: What Evidence is There About the Effects of Health Care Reforms on Gender Equity. WHO Europe: Copenhagen; 2005.

51. Sachs J: Achieving universal health coverage in low-income settings. Lancet 2012, 380:944-947.

52. WHO: The World Health Report: Health Systems Financing: The Path to Universal Coverage. Geneva: World Health Organization; 2010.

53. Kutzin J: Anything goes on the path to universal health coverage? No. Bull World Health Organ 2012, 90:867-868.

54. Mills A, Ataguba JE, Akazili J, Borghi J, Garshong B, Makaqi S, Mtei G, Harris B, Meheus JMF, McIntyre D: Equity in Financing and use of Health Care in Ghana, South Africa, and Tanzania: Implications for Paths to Universal Coverage. Lancet 2012, 280:126-133.

55. DFID: Working Effectively in Conflict-affected and Fragile Situations. London: DFID; 2010.

56. Sen G: Inequalities and Health in India. Development 2003, 46:2.

57. Bank W: Advancing Gender Equity: World Bank Action since Beijing. The World Bank: Washington; 2000.

58. Gilson L, Mills A: Health Sector Reforms in Sub-Saharan Africa: Lessons of the Past 10 Years. Cambridge: Harvard University Press; 1995.

59. Mackintosh M, Tibandebage P: Gender and Health Sector Reform: Analytical Perspectives on the African Experience. Geneva: UNRISD; 2004

60. Missoni E, Solimano G: Towards Universal Health Coverage: the Chilean Experience. Geneva: World Health Organization; 2010

61. UNWomen: Gender Responsive Budgets. New York: UN Women; 2011.

62. Romão F, Mabunda L, Buque C, Samo G, Barca OV: Violence Against Women in Mozambique. UNIFEM: Maputo; 2007.

63. UNIFEM: Gender Equity in Health Sector Budgeting: Recommendations for Gender Responsive aid. New York: UNIFEM; 2008.

64. Kohler JC, Pavignani E, Michael M, Ovtcharenko N, Murrru M, Hill P: An examination of pharmaceutical systems in severely disrupted countries. BMC Int Health Human Rights 2012, 12:1-11.

65. Pandey A, Sengupta PG, Mondal SK, Gupta DN, Manna B, Ghosh S, Sur D, Bhattacharya SK: Gender difference in healthcare-seeking during common illnesses in a rural community of West Bengal, India. J Health Popul Nutr 2002, 20:306-311.

66. Rashed S, Johnson H, Dongier P, Moreau R, Lee C, Crepeau R, Lambert J, Jefremovas $V$, Schaffer $C$ : Determinants of the permethrin impregnated bednets (PIB) in the Republic of Benin: the role of women in the acquisition and utilization of PIBs. Soc Sci Med 1999, 49:993-1005.

67. WHO: Global Tuberculosis Control: Surveillance, Planning, Financing. Geneva: World Health Organization; 2008

68. Hudelson P: Gender differentials in tuberculosis: the role of socio-economic and cultural factors. Tuber Lung Dis 1996, 77:391-400.

69. Thorson A: Equity and Equality-Case Detection of Tuberculosis Among Women and men in Vietnam. Karolinska Institutet:: Department of Public Health Sciences; 2003

70. Cheng $G$, Tolhurst $R$, Li R, Meng Q, Tang S: Factors affecting delays in TB diagnosis in rural China: a case study in four counties in Shandong Province. Trans R Soc Trop Med Hyg 2005, 99:355-362.

71. Long NH, Johansson E, Lonnroth K, Eriksson B, Winkvist A, Diwan VK: Longer delays in tuberculosis diagnosis among women in Vietnam. Int J Tubercle Lung Dis 1999, 3:388-393.

72. Theobald S, Soonthorndhada A, Smith H, Varasiri-amorn Y: Towards Equitable and Gender Sensitive TB Care in Thailand. In Gender and Tuberculosis. Proceedings of the Second International Workshop, Nordic School of Public Health. 2002.

73. UNAIDS: Report on the Global AIDS Epidemic. Geneva: UNAIDS; 2008.

74. Bila B, Egrot M: Gender asymmetry in healthcare-facility attendance of people living with HIV/AIDS in Burkina Faso. Soc Sci Med 2009, 69:854-861.

75. Standing $\mathrm{H}$ : Gender and equity in health sector reform programmes: a review. Health Policy Plann 1997, 12:1-18.
76. Harmer A: Improving the Lives of "Half the Sky": How Political Economic and Social Factors Affect the Health of Women and Children. In 'Good Health at low cost' 25 Years on: What Makes a Successful Health System? Edited by Balabanova D, McKee M, Mills A. London: London School of Hygiene and Tropical Medicine; 2011:307-337.

77. Murthy P, Smith CL: Women's Global Health and Human Rights. Sudbury: Jones and Bartlett; 2010.

78. Hudson V, Caprioli M, Ballif Spanvill B, McDermott R, Emmett CF: The Heart of the Matter: The Security of Women and the Security of States. Int Security Winter 2008, 33:7-45.

79. Hausmann R, Tyson LD, Zahidi S: The Global Gender Gap Report. Geneva: World Economic Forum; 2011.

80. Caprioli M: Primed for violence: the role of gender inequality in predicting internal conflict. Int Stud Q 2005, 49:161-178.

81. Marshall MG, Marshall DR: Gender Empowerment and the Willingness of States to Use Force. Vienna: Center for Systemic Peace; 1999.

82. Gizelis T-I: A country of their Own: women and peacebuilding. Conflict Manage Peace Sci 2011, 28:522-542.

83. Gizelis T-1: Gender empowerment and united nations peacekeeping. J Peace Res 2009, 46:505-523.

doi:10.1186/1752-1505-8-19

Cite this article as: Percival et al:: Health systems and gender in post-conflict contexts: building back better? Conflict and Health 2014 8:19.

\section{Submit your next manuscript to BioMed Central and take full advantage of:}

- Convenient online submission

- Thorough peer review

- No space constraints or color figure charges

- Immediate publication on acceptance

- Inclusion in PubMed, CAS, Scopus and Google Scholar

- Research which is freely available for redistribution

Submit your manuscript at www.biomedcentral.com/submit
C Biomed Central 